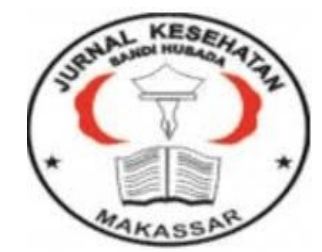

\author{
Jurnal Ilmiah Kesehatan Sandi Husada
}

hhttps://akper-sandikarsa.e-journal.id/JIKSH

Vol 11, No, 1, Juni 2020, pp;170-175

p-ISSN: 2354-6093 dan e-ISSN: 2654-4563

DOI: $10.35816 /$ jiskh.v10i2.228

\title{
Tes Toleransi Glukosa Oral Ibu Hamil Trimester II dan III Di Puskesmas Way Halim Bandar Lampung
}

The Oral Glucose Tolerance Test for Trimester II and III Pregnant Women at Way Halim Puskesmas Bandar Lampung

\section{Nabella Putri Munggaran', Fonda Octarianingsih ${ }^{2}$ Festy Ladyani ${ }^{3}$, Bambang Kurniawan 4}

1Program Studi Kedokteran, Fakultas Kedokteran Universitas Malahayati

2 ${ }^{4}$ Departemen Obstetri \& Ginekologi, Fakultas Kedokteran Universitas Malahayati

32Departemen Gizi Medik, Fakultas Kedoketran Universitas Malahayati

\section{Artikel Info}

Received;16 Maret 2020

Revised:19 Maret 2020

Accepted;20 Maret 2020

\begin{abstract}
Abstrak
Latar belakang: Tes Toleransi Glukosa Oral adalah metode yang digunakan untuk membantu mendiagnosis penyakit Diabetes Millitus Tujuan: mengetahui gambaran glukosa darah pada wanita hamil trimester II dan III di Puskesmas Way Halim Bandar Lampung Tahun 2019-2020. Metode: mengunakan jenis penelitian deskriptif analitik dengan menggunakan pendekatan deskriptif untuk mengetahui gambaran glukosa darah pada wanita hamil trimester II dan III. Teknik pengambilan sampel menggunakan metode total sampling, dengan jumlah sampel minimal yaitu sebanyak 30 sampel. Hasil: Tes Toleransi Glukosa Oral ibu hamil trimester II dan III diperoleh glukosa darah puasa $\mathrm{mg} / \mathrm{dl}$ dan setelah dilakukan Tes Toleransi Glukosa Oral didapatkan $26.67 \%$ (4 orang) yang $<90 \mathrm{mg} / \mathrm{dl}$. Usia ibu hamil rata-rata $<35$ tahun, IMT pada ibu hamil trimester II memiliki Indek Masa Tubuh normal. Gambaran paritas ibu hamil trimester II dan III adalah nulipara (<1anak) ibu hamil trimester II sebanyak 10 orang (66.67\%) dan ibu hamil trimester III sebanyak 9 orang (60\%). Riwayat abortus, ibu hamil trimester II dan trimester III tidak memiliki riwayat abortus (100\%).Ibu hamil trimester II dan trimester III tidak memiliki riwayat Diabetes Mellitus Gestasional (100\%). Riwayat Diabetes Mellitus dalam keluarga, ibu hamil trimester II dan III ada yang memiliki riwayat diabetes pada keluarga yaitu 7 orang (46.67 \%) pada Ibu Hamil Trimester II dan 6 orang ( 40\%) pada Ibu Hamil Trimester III. Riwayat melahirkan bayi makrosomnia, ibu hamil trimester II dan III ada yang memiliki riwayat kelahiran bayi makrosomia akan tetapi hanya 1 orang dari keseluruhan sampel minimal. Masing-masing ibu hamil trimester II sebanyak sebanyak 14 orang (93.3\%).15 orang (100\%) dan trimester III sebanyak 15 orang (100\%)
\end{abstract}

\section{Abstract}

Background: Oral Glucose Tolerance Test is a method used to help 
diagnose Diabetes Millitus. Purpose: knowing the picture of blood glucose in trimester II and III pregnant women at Way Halim Puskesmas Bandar Lampung in 2019-2020. Method: using descriptive analytic research using a descriptive approach to determine the description of blood glucose in pregnant women trimester II and III. The sampling technique uses total sampling method, with a minimum sample size of 30 samples. Results: Oral Glucose Tolerance Tests for second and third trimester pregnant women obtained fasting blood glucose $\mathrm{mg} \mathrm{/} \mathrm{dl}$ and after oral Glucose Tolerance Test obtained $26.67 \%$ (4 people) which $<90 \mathrm{mg} /$ $d l$. The average age of pregnant women $<35$ years, BMI in second trimester pregnant women has a normal body mass index. The parity picture of trimester II and III pregnant women is nulliparous ( $<1$ child) in trimester II pregnant women as many as 10 people (66.67\%) and trimester III pregnant women as many as 9 people (60\%). History of abortion, pregnant women trimester II and trimester III have no history of abortion (100\%), pregnant women trimester II and trimester III have no history of Gestational Diabetes Mellitus (100\%). Family history of diabetes mellitus, trimester II and III pregnant women have family history of diabetes, 7 people (46.67\%) in trimester II pregnant women and 6 people (40\%) in trimester III pregnant women. History of child macrosomnia, trimester II and III pregnant women have a history of macrosomia, but only 1 person from the total sample is minimal. Each trimester II pregnant women as many as 14 people (93.3\%), 15 people (100\%) and third trimester as many as 15 people (100\%)

Keyword:

$S P M$

ICU;

SPAF;
Coresponden author:

Email: nabellaputrimunggaran@gmail.com

artikel dengan akses terbuka dibawah lisensi CC BY -4.0

\section{Pendahuluan}

Tes Toleransi Glukosa Oral adalah metode yang digunakan untuk membantu mendiagnosis penyakit DM . Biasanya OGTT digunakan untuk mendiagnosis DM tipe 2 dan DM Gestasional (DM pada kehamilan). Pada wanita hamil OGTT dilakukan untuk mendiagnosis DM Gestasional. Diabetes Melitus Gestasional (GDM) adalah intoleransi glukosa yang dimulai pada waktu hamil (Prawirohardjo S 2010;851). Hiperglikemia dalam kehamilan dikaitkan dengan hasil ibu dan prenatal yang buruk. Penting untuk menyaring, mendiagnosis, dan mengobati Hiperglikemia pada kehamilan untuk mencegah hasil yang buruk (HAPO study 2010). Tidak ada konsensus internasional mengenai waktu metode penyaringan dan titik batas optimal untuk diagnosis dan intervensi GDM. Wanita dengan riwayat GDM juga berisiko lebih tinggi mengalami diabetes di masa depan, terutama diabetes tipe 2, seperti halnya anak-anak mereka. 
GDM mungkin memainkan peran penting dalam peningkatan prevalensi diabetes dan obesitas. Oleh karena itu, semua wanita hamil harus diskrining untuk GDM, bahkan jika mereka tidak memiliki gejala, sesuai dengan rekomendasi baru. Diperkirakan bahwa 21,3 juta atau 16,2\% kelahiran hidup untuk wanita pada 2017 memiliki beberapa bentuk hiperglikemia dalam kehamilan, 86,4\% dari kasus tersebut adalah karena diabetes gestasional mellitus (GDM), 6,2\% karena diabetes terdeteksisebelum kehamilan, dan 7,4\% karena jenis lain diabetes (termasuk diabetes tipe 1 dan tipe 2) terlebih dahulu terdeteksi pada kehamilan. 1 dari 7 kelahiran dipengaruhi oleh GDM dan sebagian besar kasus hiperglikemia dalam kehamilan terjadi di negara berpenghasilan rendah dan menengah , di mana akses ke perawatan ibu sering terbatas (IDF 2017).

Pada pemeriksaan OGTT, DIPSI (Diabetes In Pregnancy Study group India 2006) merekomendasikan pengujian dengan cara non-puasa dengan $75 \mathrm{~g}$ glukosa dengan cut-off $\geq 140 \mathrm{mg} / \mathrm{dl}$ setelah 2 jam, sedangkan WHO (1999) merekomendasikan OGTT puasa setelah glukosa $75 \mathrm{~g}$ dengan plasma cut-off glukosa $\geq 140 \mathrm{mg} / \mathrm{dl}$ setelah $2 \mathrm{jam}$. National Institute of Clinical Excellence 2015 juga merekomendasikan untuk mendiagnosis GDM dengan 75 g glukosa oral. Pada pemeriksaan OGTT, DIPSI (Diabetes In Pregnancy Study group India 2006) merekomendasikan pengujian dengan cara non-puasa dengan $75 \mathrm{~g}$ glukosa dengan cut-off $\geq 140 \mathrm{mg} / \mathrm{dl}$ setelah 2 jam, sedangkan WHO (1999) merekomendasikan OGTT puasa setelah glukosa $75 \mathrm{~g}$ dengan plasma cut-off glukosa $\geq 140$ $\mathrm{mg} / \mathrm{dl}$ setelah 2 jam. National Institute of Clinical Excellence 2015 juga merekomendasikan untuk mendiagnosis GDM dengan 75 g glukosa oral. Sementara praktik standar adalah untuk menguji wanita hamil untuk GDM antara 24 dan 28 minggu kehamilan, ada bukti yang menunjukkan bahwa banyak wanita memanifestasikan hiperglikemia di awal kehamilan sebagai konsekuensi dari diabetes yang sebelumnya tidak diketahui atau tingkat resistensi insulin yang lebih tinggi dan kapasitas yang berkurang untuk meningkatkan sekresi insulin menghasilkan dekompensasi sebelumnya yang bermanifestasi sebagai onset awal GDM.

Setiap tingkat intoleransi glukosa selama kehamilan dikaitkan dengan hasil ibu dan janin yang buruk. Status berisiko rendah tidak memerlukan pengujian glukosa, tetapi kategori ini terbatas pada wanita yang memenuhi semua karakteristik berikut: Usia <25 tahun,berat badan normal sebelum hamil, anggota kelompok etnis dengan prevalensi GDM rendah, tidak ada diabetes yang diketahui pada kerabat tingkat pertama, tidak ada riwayat toleransi glukosa abnormal,tidak ada riwayat hasil kebidanan yang buruk.

Komplikasi maternal yang merugikan termasuk hipertensi, preeklampsia, infeksi saluran kemih, hidramnion, peningkatan intervensi operasi dan DM di masa depan. Pada janin dan neonatus dikaitkan dengan makrosomia, kelainan bawaan, kelainan metabolik, dll. Dan obesitas pada masa kanak-kanak dan remaja. Oleh karena itu, penting untuk mendiagnosis secara dini dan mengobati segera untuk mencegah komplikasi,

\section{Metode Penelitian}

Desain penelitian ini menggunakan pendekatan deskriptif. Teknik pengambilan sampel pada penelitian ini menggunakan metode total sampling dan didapatkan jumlah sampel sebanyak 30 orang. Kriteria inklusi: Ibu hamil Trimester II Akhir (20-24 minggu) dan Trimester III (28-40 minggu) dan bersedia menjadi responden. Kriteria eksklusi: Ibu Hamil dengan riwayat DM sebelumnya, ibu hamil yang minum obat anti Diabetes. 


\section{Hasil Penelitian dan Pembahasan}

\section{Analisis Tes Toleransi Glukosa Oral pada Ibu Hamil Trimester II dan III di} Puskesmas Way Halim Kecamatan Way Halim Bandar Lampung Tahun 2020

\begin{tabular}{ccccc}
\hline \multirow{2}{*}{$\begin{array}{c}\text { Tes Toleransi } \\
\text { Glukosa Oral }\end{array}$} & \multicolumn{2}{c}{ Trimester II } & \multicolumn{2}{c}{ Trimester III } \\
\cline { 2 - 5 } & $\mathrm{N}$ & $\%$ & $\mathrm{n}$ & $\%$ \\
\hline $80-90 \mathrm{mg} / \mathrm{dl}$ & 4 & 26.67 & 4 & 26.66 \\
$91-100 \mathrm{mg} / \mathrm{dl}$ & 7 & 46.66 & 4 & 26.67 \\
$101-110 \mathrm{mg} / \mathrm{dl}$ & 3 & 20.0 & 4 & 26.67 \\
$111-120 \mathrm{mg} / \mathrm{dl}$ & 1 & 6.67 & & \\
$121-130 \mathrm{mg} / \mathrm{dl}$ & & & 2 & 13.33 \\
$131-140 \mathrm{mg} / \mathrm{dl}$ & & & & \\
$141-150 \mathrm{mg} / \mathrm{dl}$ & & & 1 & 6.67 \\
\hline Total & 15 & 100 & 15 & 100 \\
\hline
\end{tabular}

Dari hasil penelitian di atas memperlihatkan gula darah puasa ibu hamil sebagian besar normal (<92 mg/dl) yaitu 10 orang $(66.67 \%$ ) dan ada yang diatas normal ( $\geq 92 \mathrm{mg} / \mathrm{dl}$ ) berjumlah 5 orang (33.33\%). Dan hasil Tes Toleransi Glukosa Oral Pada Ibu Hamil Trimester II dan III rata-rata normal $(<140 \mathrm{mg} / \mathrm{dl})$ berjumlah 14 orang $(93.33 \%)$ dan terdapat 1 orang (6.67\%) yang hasil dari OGTT $(\geq 140 \mathrm{mg} / \mathrm{dl}$ ) yang terdiagnosis Diabetes Mellitus Gestasional.

Hal ini berdasarkan pedoman DIPSI (Diabetes In Pregnancy Study Group India 2006) merekomendasikan pengujian dengan cara non-puasa dengan 75 g glukosa dengan cut-off $>140 \mathrm{mg} / \mathrm{dl}$ setelah 2 jam. Menurut kriteria Organisasi Kesehatan Dunia (WHO 2013), GDM didiagnosis menggunakan $75 \mathrm{~g}$ OGTT dengan nilai glukosa plasma puasa $>126 \mathrm{mg} / \mathrm{dl}$ atau dua jam> $140 \mathrm{mg} / \mathrm{dl}$. Dan menurut kriteria IADPSG (Implementation of the International Association of Diabetes and Pregnancy Study Groups), diagnosis GDM didasarkan pada salah satu dari kriteria berikut, yaitu puasa $>92 \mathrm{mg} / \mathrm{dl}, 1 \mathrm{jam} \geq 180$ $\mathrm{mg} / \mathrm{dl}$ dan 2 jam $\geq 153 \mathrm{mg} / \mathrm{dl}$ dalam keadaan puasa, dan ini disebut sebagai kriteria IADPSG (Implementation of the International Association of Diabetes and Pregnancy Study Groups).

National Institute of Clinical Excellence 2015 juga merekomendasikan untuk mendiagnosis GDM (Gestasional Diabetes Mellitus) dengan 75 g glukosa oral. Dalam penelitian ini, maka diambil kriteria IADPSG (Implementation of the International Association of Diabetes and Pregnancy Study Groups) sebagai GDP (Gula Darah Puasa)dan kriteria $\geq 92 \mathrm{mg} / \mathrm{dl}$. Dan WHO (World Health Organization) dengan nilai OGTT $>140 \mathrm{mg} / \mathrm{dl}$ sebagai langkah awal diagnosa GDM (Gestasional Diabetes Mellitus).

Usia, dari hasil penelitian dapat dilihat sebagian besar kelompok usia ibu hamil trimester II dan III adalah usia tidak berisiko ( 235 tahun). Masing-masing ibu hamil trimester II sebanyak 12 orang (80\%) dan trimester III sebanyak 12 orang (80\%). Meskipun menurut IDF (2017) hiperglikemia dalam kehamilan cenderung terjadi pada usia >30 tahun terutama di negara berkembang atau berpenghasilan rendah. Akan tetapi risiko lebih tinggi bisa terjadi pada usia $\geq 35$ tahun (Renata Selbach et al 2015).

Berdasarkan hasil penelitian dapat dilihat sebagian besar IMT ibu hamil trimester II dan III adalah normal. Masing-masing sebagian besar IMT Ibu Hamil Trimester II memiliki IMT normal yaitu 12 orang (80\%), dan Ibu Hamil Trimester III sebagian besar yaitu 9 orang $(60 \%)$ yang mengalami Overweight.

Dalam jurnal Risk factors for gestational diabetes mellitus in a sample of pregnant women diagnosed with the disease ( Renata Selbach et al 2015 ) disebutkan kelebihan berat badan Nabella Putri Munggaran, etall, The Oral Glucose Tolerance Test for Trimester II and III Pregnant Women at Way Halim Puskesmas Bandar Lampung, jiksh Vol.11 No.1 Juni 2020 
atau obesitas, kenaikan berat badan kehamilan yang berlebihan, deposisi lemak tubuh pusat yang berlebihan menjadi faktor risiko dalam Diabetes Mellitus Gestasional.

Riwayat paritas, berdasarkan penelitian di atas dapat dilihat sebagian besar riwayat paritas ibu hamil trimester II dan III adalah nulipara (<1anak) ibu hamil trimester II sebanyak 10 orang $(66.67 \%)$ dan ibu hamil trimester III sebanyak 9 orang (60\%). Menurut Prawirohardjo (2010) nullipara dan multipara (lebih dari 3) mempunyai angka kematian maternal lebih tinggi. Makin tinggi paritas ibu (Grandemultipara) semakin kurang baik endometrium. Ini diakibatkan oleh vaskularisasi yang berkurang ataupun perubahan atrofi pada desidua akibat yang lampau sehingga dapat mengakibatkan terjadinya komplikasi persalinan.

Riwayat diabetes gestasional, berdasarkan penelitian dapat dilihat seluruh ibu hamil trimester II dan trimester III tidak memiliki riwayat diabetes mellitus gestasional (100\%). Meskipun begitu, riwayat Diabetes Mellitus Gestasional pada kehamilan sebelumnya menjadi faktor pemicu terjadinya kembali Diabetes Mellitus Gestasional pada kehamilan sekarang (Eman M Alfadhali 2014).

Riwayat Diabetes Keluarga, berdasarkan penelitian di atas dapat dilihat seluruh responden ada yang memiliki dan tidak memiliki riwayat diabetes keluarga . Ibu hamil trimester II dan III ada yang memiliki riwayat diabetes pada keluarga yaitu 7 orang (46.67 \%) pada Ibu Hamil Trimester II dan 6 orang ( 40\%) pada Ibu Hamil Trimester III . Riwayat diabetes dalam keluarga menjadi salah satu faktor risiko atau pemicu terjadinya Diabetes Mellitus Gestasional (Renata Selbach et al 2015).

Riwayat kelahiran bayi makrosomia, berdasarkan hasil penelitian di atas dapat dilihat sebagian besar ibu hamil trimester II dan III tidak memiliki riwayat kelahiran bayi makrosomia. Masing-masing ibu hamil trimester II sebanyak 15 orang (100\%) dan trimester III sebanyak 14 orang (93.3\%) hanya 1 responden ibu hamil trimester III yang terdeteksi dalam riwayat makrosomia (6.7\%). Meskipun begitu kelahiran bayi makrosomnia (berat lahir $\geq 4000 \mathrm{~g}$ ), menjadi salaah satu faktor risiko terjadinya Diabetes Mellitus Gestasional ( Eman M Alfadhali 2014).

Tekanan darah, berdasarkan hasil penelitian dapat dilihat sebagian besar tekanan darah ibu hamil sebelum dan sesudah puasa adalah normal $(>120 / 80 \mathrm{mg} / \mathrm{dl})$. Masing-masing tekanan darah normal ibu hamil trimester II sesudah puasa sebanyak13 orang (86.7dan ibu hamil trimester III sebanyak 13 orang (86.7\%). Dikutip dari AHA ( American Heart Asociation ) tekanan darah normal adalah $<120 / 80 \mathrm{mmHg}$. Dan menurut ACOG ( American College Obstetri Ginecologi) Hipertensi gestasional adalah tekanan darah tinggi yang pertama kali terjadi setelah 20 minggu kehamilan. Untuk pedoman tekanan darah normal adalah sebagai berikut; Pedoman untuk pengukuran tekanan darah adalah sebagai berikut; Normal: Kurang dari 120/80 mm Hg, Tinggi: Sistolik antara 120-129 dan diastolik kurang dari $80 \mathrm{~mm} \mathrm{Hg}$, Stadium 1 hipertensi: Sistolik antara 130-139 atau diastolik antara 80-89 mm Hg,Stadium 2 hipertensi: Sistolik setidaknya 140 atau diastolik setidaknya 90 $\mathrm{mm} \mathrm{Hg}$.

\section{Kesimpulan dan Saran}

Berdasarkan hasil penelitian memperlihatkan gula darah puasa ibu hamil sebagian besar normal $<92 \mathrm{mg} / \mathrm{dl}$ ) yaitu 10 orang $(66.67 \%$ ) dan ada yang diatas normal ( $\geq 92 \mathrm{mg} / \mathrm{dl}$ ) berjumlah 5 orang ( $33.33 \%$ ). Gambaran Tes Toleransi Glukosa Oral pada Ibu Hamil Trimester II GDP ( Gula Darah Puasa) 15 orang (100\%) <92 mg/dl. Sedangkan setelah dilakukan Tes Toleransi Glukosa Oral hanya 4 orang (26.67\%) yang gula darahnya $<92$ mg/dl. Pada Ibu Hamil Trimester III GDP (Gula Darah Puasa) 10 orang $(66.67 \%)<90$ mg/dl. Dan setelah dilakukan Tes Toleransi Glukosa Oral hanya 4 orang (26.67\%) yang 
gula darahnya $<90 \mathrm{mg} / \mathrm{dl}$.

Gambaran tes toleransi glukosa oral pada ibu hamil trimester II dan trimester III dipengaruhi oleh riwayat yang dimiliki ibu hamil. Bagi peneliti selanjutnya, karena tidak semua ibu hamil mau melakukan tes toleransi glukosa oral maka perlu diberikan edukasi terlebih dahulu tentang skrinning Diabetes Mellitus Gestasional dan pentingnya melakukan Tes Toleransi Glukosa oral sebagai langkah awal penegakan diagnosa jika ibu hamil mengalami Diabetes Mellitus Gestasional.

\section{DAFTAR PUSTAKA}

Atlas, D. International Diabetes Federation 2017. IDF Diabetes Atlas, 8th edn. .

Bartoli, E., Fra, G. P., \& Schianca, G. C. (2011). The oral glucose tolerance test (OGTT) revisited. European journal of internal medicine, 22(1), 8-12.

Benhalima, K., Minschart, C., Van Crombrugge, P., Calewaert, P., Verhaeghe, J., Vandamme, S., ... \& Dufraimont, E. (2019). The 2019 Flemish consensus on screening for overt diabetes in early pregnancy and screening for gestational diabetes mellitus. Acta Clinica Belgica, 1-8.

Bender, W., Hirshberg, A., \& Levine, L. D. (2019). Interpregnancy Body Mass Index Changes: Distribution and Impact on Adverse Pregnancy Outcomes in the Subsequent Pregnancy. American journal of perinatology, 36(05), 517-521.

Liu, Z. Y., Zhao, J. J., Gao, L. L., \& Wang, A. Y. (2019). Glucose screening within six months postpartum among Chinese mothers with a history of gestational diabetes mellitus: a prospective cohort study. BMC pregnancy and childbirth, 19(1), 134.

Horsch, A., Gilbert, L., Lanzi, S., Kang, J. S., Vial, Y., \& Puder, J. J. (2019). Prospective associations between maternal stress during pregnancy and fasting glucose with obstetric and neonatal outcomes. Journal of psychosomatic research, 109795.

Metzger, B. E., Coustan, D. R., \& Trimble, E. R. (2019). Hyperglycemia and adverse pregnancy outcomes. Clinical chemistry, 65(7), 937-938.

Notoatmodjo, S. (2016). Metodologi penelitian kesehatan, Jakarta : Rineka Cipta

Ovesen, P. G., Jensen, D. M., Damm, P., Rasmussen, S., \& Kesmodel, U. S. (2015). Maternal and neonatal outcomes in pregnancies complicated by gestational diabetes. A nationwide study. The Journal of Maternal-Fetal \& Neonatal Medicine, 28(14), 1720-1724.

Pons, R. S., Rockett, F. C., de Almeida Rubin, B., Oppermann, M. L. R., \& Bosa, V. L. (2015). Risk factors for gestational diabetes mellitus in a sample of pregnant women diagnosed with the disease. Diabetology \& metabolic syndrome, 7(91).

Sacks, D. A., Hadden, D. R., Maresh, M., Deerochanawong, C., Dyer, A. R., Metzger, B. E., ... \& Persson, B. (2012). Frequency of gestational diabetes mellitus at collaborating centers based on IADPSG consensus panel-recommended criteria: the Hyperglycemia and Adverse Pregnancy Outcome (HAPO) Study. Diabetes care, 35(3), 526-528.

Sarwono Prawirohardjo (2010), Ilmu Kebidanan : Diabetes Mellitus Gestasional dan Kehamilan.

Sudoyo, A. W., Setiyohadi, B., Alwi, I., Simadibrata, M., \& Setiati, S. (2015). Buku Ajar Ilmu Penyakit Dalam Jilid II edisi V. Jakarta: Interna Publishing, 310, 1973-1982.

Wid, S., Roglic, G., Green, A., Sicree, R., \& King, H. (2004). Global prevalence of diabetes. Edinburgh: Diabetes Care, 27(5), 1050-1051.

Van Quan, N., Xuan, T. D., Tran, H. D., Thuy, N. T. D., Trang, L. T., Huong, C. T., ... \& Tuyen, P. T. (2019). Antioxidant, $\alpha$-Amylase and $\alpha$-Glucosidase Inhibitory Activities and Potential Constituents of Canarium tramdenum Bark. Molecules, 24(3). 